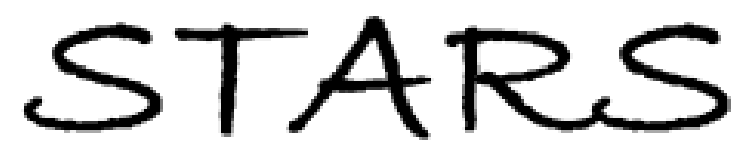

University of Central Florida

STARS

$1-1-2003$

\title{
Martian impact crater ejecta morphologies as indicators of the distribution of subsurface volatiles
}

Nadine G. Barlow

Carola B. Perez

University of Central Florida

Find similar works at: https://stars.library.ucf.edu/facultybib2000

University of Central Florida Libraries http://library.ucf.edu

This Article is brought to you for free and open access by the Faculty Bibliography at STARS. It has been accepted for inclusion in Faculty Bibliography 2000 s by an authorized administrator of STARS. For more information, please contact STARS@ucf.edu.

\section{Recommended Citation}

Barlow, Nadine G. and Perez, Carola B., "Martian impact crater ejecta morphologies as indicators of the distribution of subsurface volatiles" (2003). Faculty Bibliography 2000s. 3606.

https://stars.library.ucf.edu/facultybib2000/3606

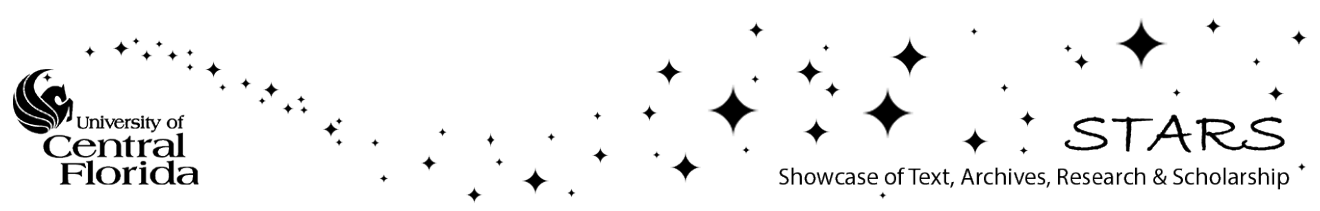




\title{
Martian impact crater ejecta morphologies as indicators of the distribution of subsurface volatiles
}

\author{
Nadine G. Barlow \\ Department of Physics and Astronomy, Northern Arizona University, Flagstaff, Arizona, USA \\ Carola B. Perez \\ College of Engineering and Computer Science, University of Central Florida, Orlando, Florida, USA \\ Received 20 December 2002; revised 14 April 2003; accepted 19 May 2003; published 9 August 2003.
}

[1] Fresh Martian impact craters display a variety of ejecta blanket morphologies. The fluidized appearance of most fresh ejecta types is commonly ascribed to heating and vaporization of subsurface volatiles during crater formation. We have conducted a study of the distribution of the three dominant fluidized ejecta morphologies (single layer ejecta (SLE), double layer ejecta (DLE), and multiple layer ejecta (MLE)) within the $\pm 60^{\circ}$ latitude zone on Mars. We have subdivided this region into $5^{\circ} \times 5^{\circ}$ latitude-longitude boxes and have computed the following for each box: (1) percentage of craters showing any ejecta morphology as a function of total number of craters, (2) percentage of SLE craters as a function of craters with an ejecta morphology, (3) percentage of DLE craters as a function of craters with an ejecta morphology, and (4) percentage of MLE craters as a function of craters with an ejecta morphology. We confirm previous reports that the SLE morphology is the most common ejecta type within the study area, constituting $>70 \%$ of all ejecta morphologies over most of the study area. The DLE and MLE morphologies are much less common, but these morphologies are concentrated in localized regions of the planet. Using these results, we discuss how subsurface volatile reservoirs may be distributed across the planet. The regional variations found in this study generally correlate with the proposed locations of near-surface $\mathrm{H}_{2} \mathrm{O}$ reservoirs detected by Mars

Odyssey. INDEX TERMS: 6225 Planetology: Solar System Objects: Mars; 5420 Planetology: Solid Surface Planets: Impact phenomena (includes cratering); 5470 Planetology: Solid Surface Planets: Surface materials and properties; 5764 Planetology: Fluid Planets: Surfaces; KEYWORDS: Martian craters, Martian volatiles, crater ejecta, Mars

Citation: Barlow, N. G., and C. B. Perez, Martian impact crater ejecta morphologies as indicators of the distribution of subsurface volatiles, J. Geophys. Res., 108(E8), 5085, doi:10.1029/2002JE002036, 2003.

\section{Martian Ejecta Morphologies}

[2] Viking and Mars Global Surveyor (MGS) imagery clearly show that fresh impact craters on Mars are commonly surrounded by a layered or lobate ejecta morphology, unlike the radial patterns seen around fresh craters on the Moon and Mercury. Two proposals exist to explain the origin of these lobate morphologies: impact into and vaporization of subsurface volatiles [Carr et al., 1977; Gault and Greeley, 1978; Greeley et al., 1980; Wohletz and Sheridan, 1983; Mouginis-Mark, 1987] or ejecta entrainment into the thin Martian atmosphere [Schultz and Gault, 1979; Barnouin-Jha and Schultz, 1998]. While computer modeling shows that the ejecta entrainment hypothesis is viable and is almost certainly responsible for the ejecta morphologies seen surrounding fresh impact craters on Venus [Schultz, 1992], the subsurface volatile hypothesis is supported by the observed diameter and latitudinal variations of

Copyright 2003 by the American Geophysical Union. 0148-0227/03/2002JE002036 the ejecta morphologies [Allen, 1978; Johansen, 1978, 1979; Mouginis-Mark, 1979; Saunders and Johansen, 1980; Costard, 1989; Barlow and Bradley, 1990] and the sinuosity variations among different ejecta types [Kargel, 1989; Barlow, 1994]. Boyce and Roddy [1997] review the collection of evidence supporting the idea that subsurface volatiles are responsible for the fluidized ejecta morphologies. Recent hydrocode simulations suggest that both mechanisms contribute to the formation of the layered ejecta morphologies on Mars, but subsurface volatiles appear be the dominant contributor, particularly for the single layer morphology (the most common type of ejecta morphology seen on Mars) [Baratoux et al., 2002; S. T. Stewart et al., Impact processing and redistribution of near-surface water on Mars, submitted to Nature, 2003 (hereinafter referred to as Stewart et al., submitted manuscript, 2003)].

[3] Martian impact crater ejecta morphologies have been classified on the basis of their range of appearances [Head and Roth, 1976; Johansen, 1979; Mouginis-Mark, 1979; Blasius and Cutts, 1980; Horner and Greeley, 1987; Costard, 1989; Barlow and Bradley, 1990]. In an effort to standardize 

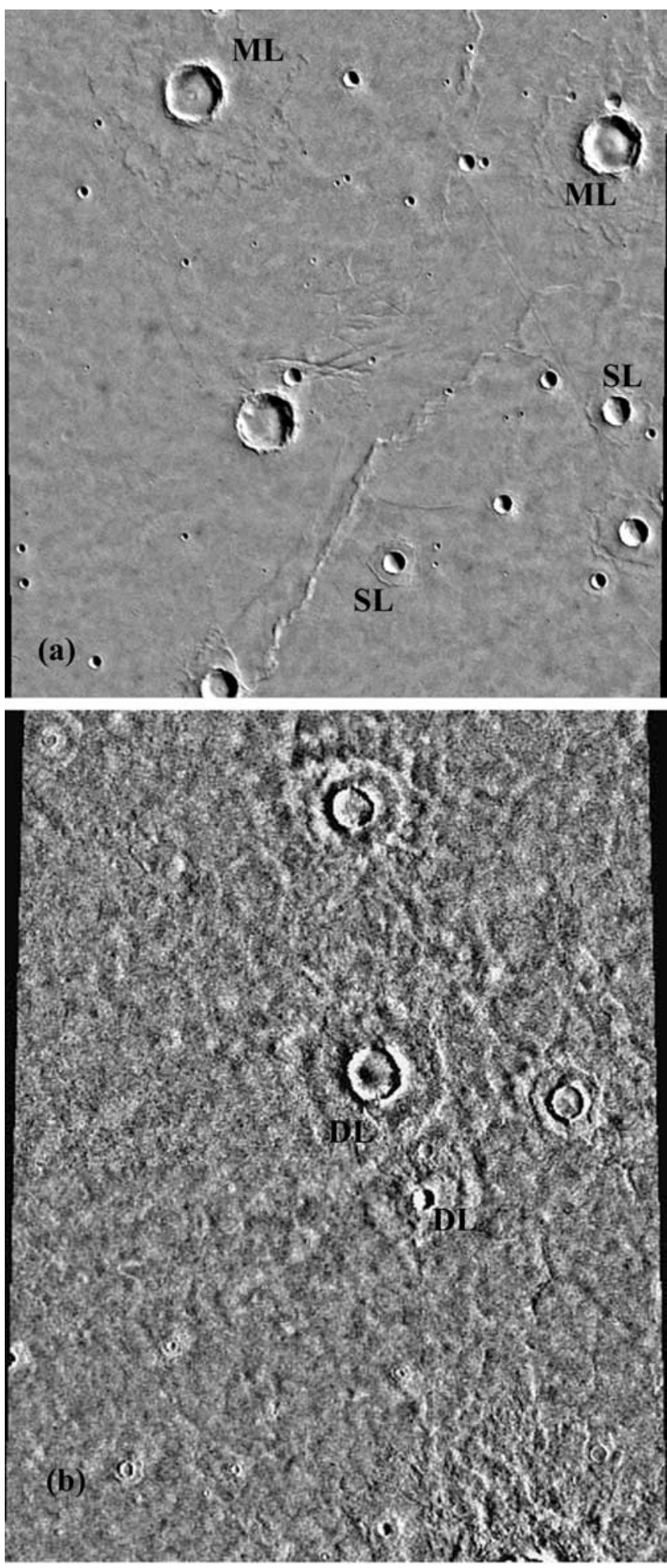

Figure 1. Examples of ejecta morphologies. (a) Examples of the SLE and MLE ejecta morphologies. MLE crater at upper right is located at $16.0^{\circ} \mathrm{S} 275.4^{\circ} \mathrm{E}$ and is $18.8 \mathrm{~km}$ in diameter. SLE crater is located at $18.7^{\circ} \mathrm{S} 276.6^{\circ} \mathrm{E}$ and is 7.4 $\mathrm{km}$ in diameter. (b) Example of the DLE morphology. Central DLE crater is $13.8 \mathrm{~km}$ in diameter and is located at $41.3^{\circ} \mathrm{N} 98.3^{\circ} \mathrm{E}$. the nomenclature used by the community when discussing these features, the Mars Crater Morphology Consortium recommends a classification system which avoids references to the possible origins of these features [Barlow et al., 2000]. Thus "fluidized morphology" has been replaced by "layered morphology", to reflect the presence of one or more continuous layers of material and avoiding any implications of the process(es) involved in creating these morphologies. Using this nomenclature system, our present study focuses on the regional variations of the three major layered ejecta morphologies: single layer ejecta (SLE), double layer ejecta (DLE), and multiple layer ejecta (MLE) (Figure 1). SLE craters are characterized by one continuous layer of material surrounding the crater. DLE craters have two complete layers of material surrounding the crater, with the inner layer typically superimposed upon the outer layer. MLE craters display three or more partial or complete layers of material.

[4] Many studies have previously reported on the latitudinal distribution [Johansen, 1978, 1979; Mouginis-Mark,

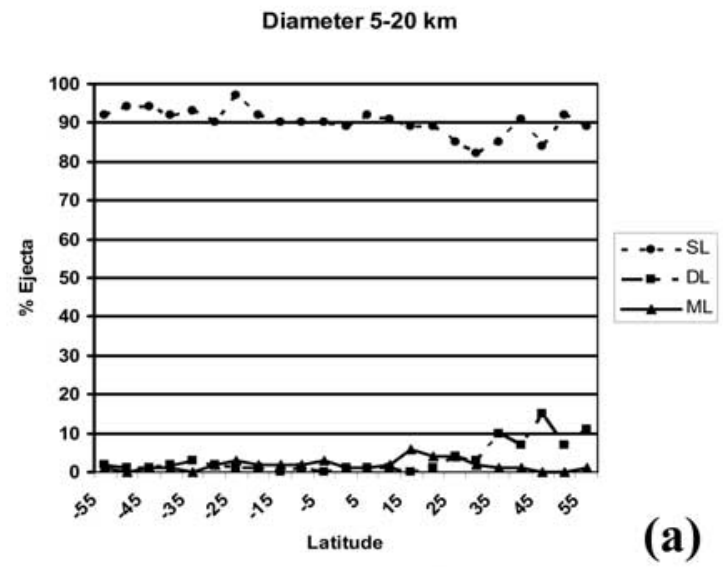

Diameter $>20 \mathrm{~km}$

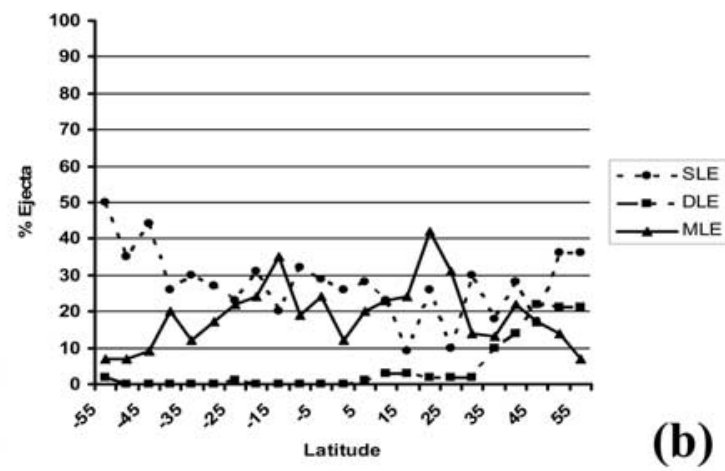

Figure 2. Correlation of ejecta type with latitude and diameter. These graphs should the mean diameter of SLE, DLE, and MLE craters as a function of latitude. Results are averaged over $10^{\circ}$ latitude zones between $\pm 70^{\circ}$. (a) This graph shows the latitudinal distribution for craters between 5 and $20 \mathrm{~km}$ in diameter. (b) This graph shows the latitudinal distribution for craters greater than $20 \mathrm{~km}$ in diameter. 

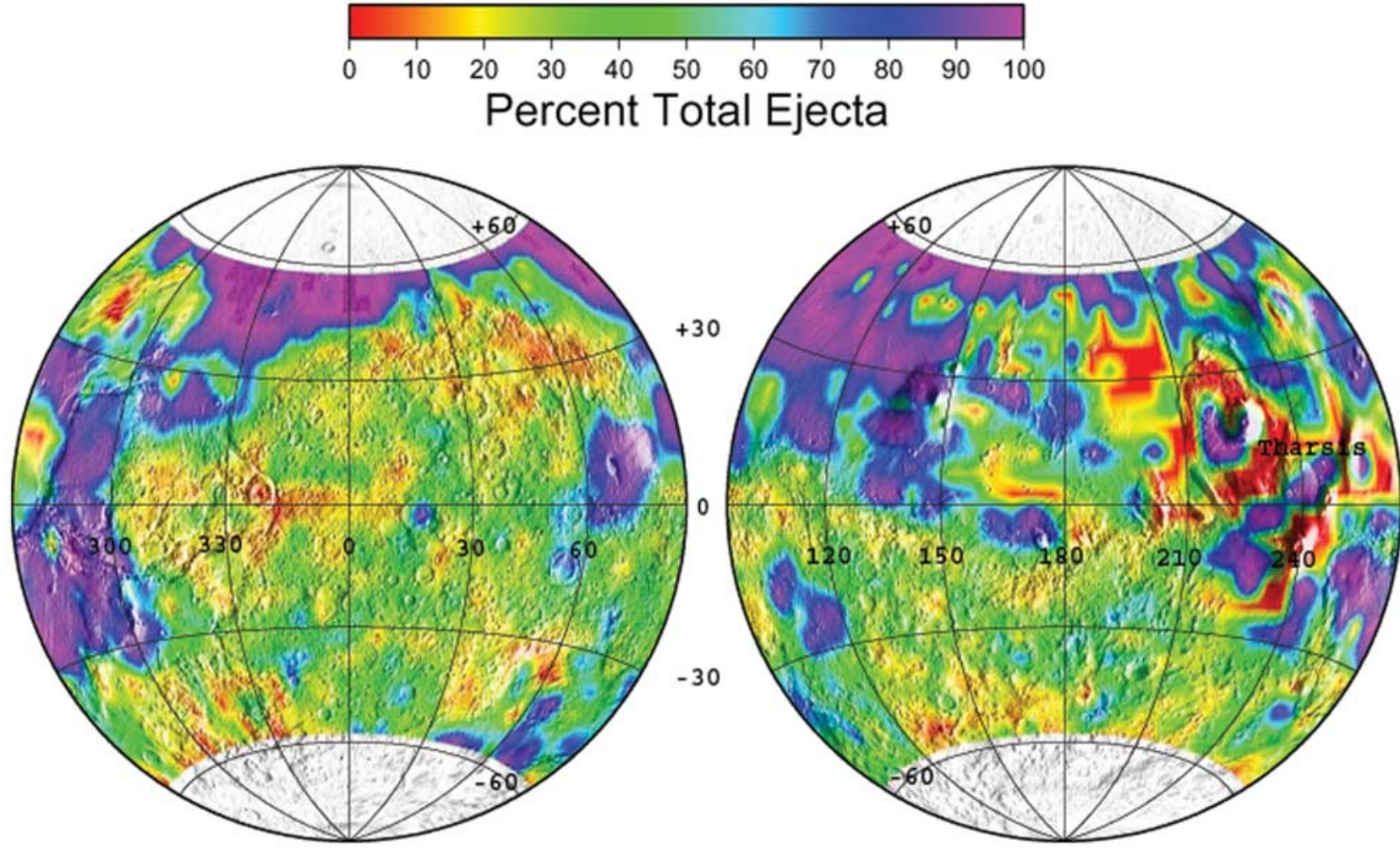

Figure 3. Percentage of ejecta craters. This map shows the distribution of craters showing some type of ejecta morphology as a function of total number of craters in each $5^{\circ} \times 5^{\circ}$ latitude-longitude box. As discussed in the text, regions generally correlate with the stratigraphic ages (Noachian, Hesperian, and Amazonian).

1979; Blasius and Cutts, 1980; Saunders and Johansen, 1980; Costard, 1989; Barlow and Bradley, 1990] and sinuosity [Kargel, 1989; Barlow, 1994] of these layered ejecta morphologies. Studies by ourselves and other researchers have led us to conclude that subsurface volatiles play a dominant role in the formation of these features. For example, Barlow and Bradley [1990] found a strong diameter-latitude correlation for the SLE and MLE craters, which is consistent with the proposed distribution of subsurface ice and liquid water based on geothermal models. As seen in Figure 2, SLE morphologies dominate for craters $\leq 20-\mathrm{km}-$ diameter in the $\pm 30^{\circ}$ latitude zone (regardless of terrain) while MLE morphologies are found around craters between $20 \mathrm{~km}$ and $45 \mathrm{~km}$ in diameter in the same latitude zone. SLE morphologies dominate at all but the largest crater diameters at higher latitudes, except in the $40^{\circ} \mathrm{N}$ to $65^{\circ} \mathrm{N}$ latitude zone where the DLE morphologies dominate. Using accepted depth-diameter relationships [Croft, 1980; Melosh, 1989], Barlow and Bradley [1990] found that SLE craters excavate into the zone proposed to consist primarily of ice, whereas MLE craters excavate to depths which could contain liquid reservoirs on the basis of geothermal models for the planet [Fanale, 1976; Clifford, 1993]. They thus proposed that the morphology of Martian impact crater ejecta blankets provided information about the distribution and physical state of the subsurface volatiles. Alternately, Boyce et al. [2000] have argued that layered ejecta morphologies displaying a distal rampart (including many SLE craters) result from excavation into water-rich regions while non-rampart mor- phologies result from impact into ice. However, topographic analysis from the Mars Orbiter Laser Altimeter (MOLA) instrument indicate that all layered ejecta morphologies display a distal rampart even if one is not obvious in visible images [Barlow et al., 2000]. Recent hydrocode modeling by Stewart et al. (submitted manuscript, 2003) suggests that the SLE morphology results from impact into ice and the MLE morphology results from interactions between the ejecta curtain (enriched with volatiles from the subsurface) and the atmosphere. Thus there is still considerable controversy over whether ejecta morphology can provide information about the physical state of the volatiles encountered during crater formation.

[5] Many researchers have utilized the theory that the layered ejecta morphologies result from impact into subsurface volatile reservoirs to investigate the characteristics of buried ice and water on Mars. Boyce and Roddy [1978], Kuzmin et al. [1988], Boyce et al. [1998, 2000], Demura and Kurita [1998], and Barlow et al. [2001] have investigated the depths to subsurface volatile reservoirs using the onset diameters of different layered ejecta morphologies. Mutch and Woronow [1980], Woronow [1981], Mouginis-Mark [1979, 1981], and Costard [1989] have argued that the extent of the layered ejecta blankets provides information about the concentration of volatiles incorporated into the ejecta curtain. Gault and Greeley [1978], Greeley et al. [1980], Mouginis-Mark [1981], Wohletz and Sheridan [1983], Baratoux et al. [2002], and Stewart et al. (submitted manuscript, 2003) have modeled the emplacement process 

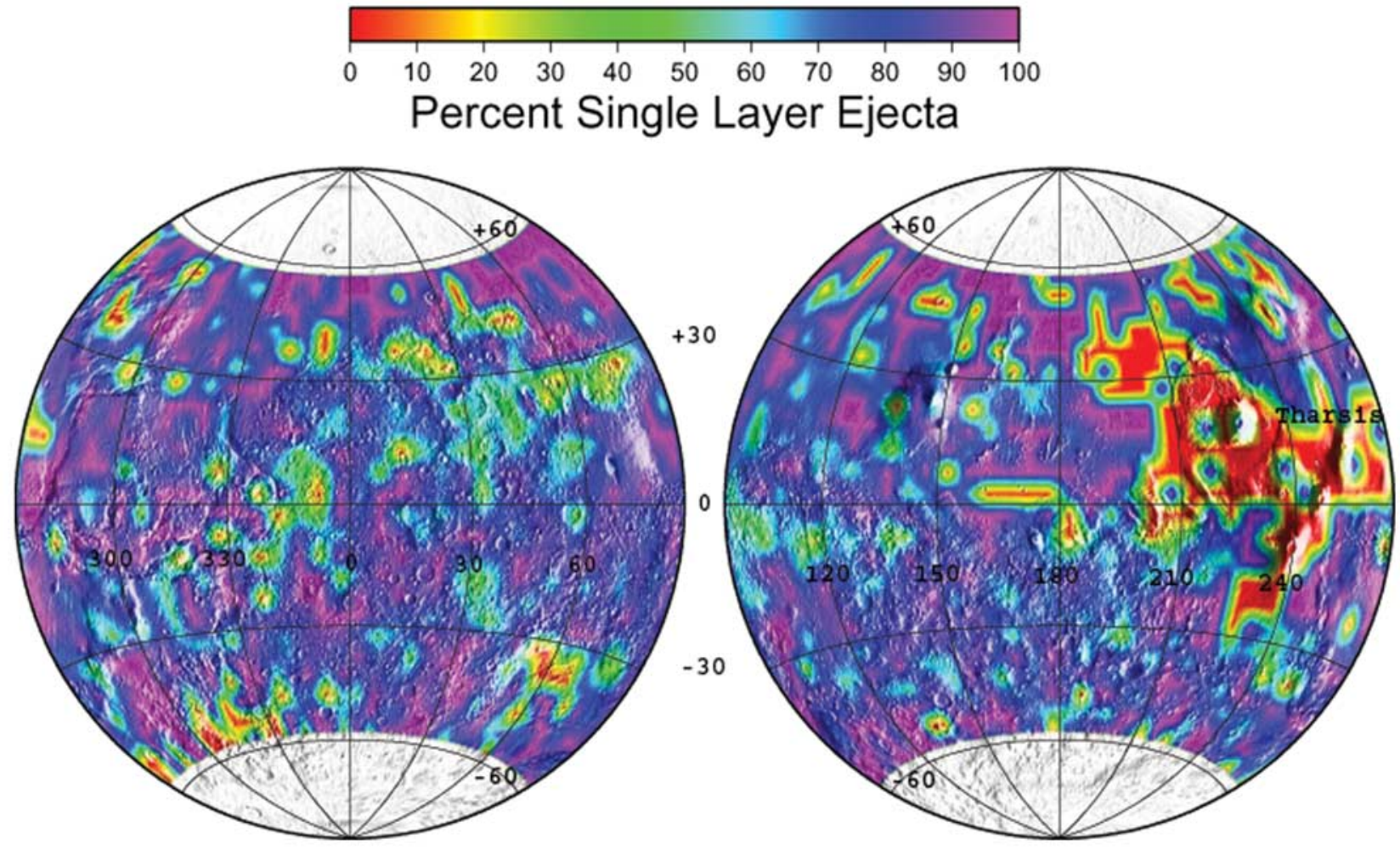

Figure 4. Percentage of SLE craters. This map shows the distribution of SLE craters as a function of total number of ejecta craters in each $5^{\circ} \times 5^{\circ}$ latitude-longitude box. SLE craters generally constitute $70 \%$ or more of the ejecta craters in most locations within this study area- the notable exception is the Tharsis region, where very few craters of any type occur.

of the single layer ejecta blankets and find that incorporation of varying amounts of subsurface $\mathrm{H}_{2} \mathrm{O}$ can accurately reproduce the qualitative and quantitative characteristics of these features.

[6] Regional variations in the distribution of subsurface volatile reservoirs have also been reported. Lucchitta and Fergusson [1983], Costard [1989, 1994], Costard and Kargel [1995], Demura and Kurita [1998], and Head et al. [1998] have used correlations of rampart craters with other putative indicators of ice-rich material (e.g., polygonal and mottled terrain) to argue for enhanced ice content in Chryse Planitia and Utopia Planitia. Kuzmin et al. [1988], Demura and Kurita [1998], Boyce et al. [2000], and Barlow et al. [2001] find regional variations in the onset diameter of SLE craters, suggesting that the depth to the ice-rich reservoir varies even through the equatorial region.

[7] In recent years there has been increasing debate as to whether the Martian subsurface volatiles are composed of water, carbon dioxide, or other compounds [Malin and Edgett, 2000; Hoffman, 2000; Musselwhite et al., 2001; Max and Clifford, 2001]. However, Stewart and Nimmo [2002] find that neither condensed $\mathrm{CO}_{2}$ or $\mathrm{CO}_{2}$ clathrate hydrate are likely to accumulate or remain stable in the Martian near-surface in sufficient quantities under the current climatic conditions. They also find that exposure of any condensed $\mathrm{CO}_{2}$ to the present atmospheric conditions would result in features similar to pyroclastic flow, not the gullies and outflow channels that are seen on Mars. Methane clathrates, as proposed by Max and Clifford [2001], are even more difficult to produce in large quantities without an extensive Martian biosphere, for which there currently is no evidence. These results, together with those from the Mars Odyssey Gamma Ray Spectrometer (GRS) experiment [Boynton et al., 2002; Feldman et al., 2002], suggest that $\mathrm{H}_{2} \mathrm{O}$ is the dominant volatile in the Martian substrate.

[8] This study differs from the previous regional analyses in (1) utilizing all three of the major layered ejecta morphologies (i.e., SLE, DLE, and MLE) designated by the Mars Crater Morphology Consortium, (2) defining these morphologies on the basis of data from the Mars Global Surveyor mission, and (3) comparing the results with those from the Gamma Ray Spectrometer instrument suite aboard the Mars Odyssey mission. Our technique is similar to that which we employed in previous global studies: look at the statistical variation in the concentrations of particular ejecta morphologies to determine where regional anomalies in subsurface volatile concentrations may occur and use the onset diameters to estimate the depths of the volatile reservoir(s). Our results show that regional variations exist for the DLE and MLE morphologies which correlate with other evidence of near-surface volatile reservoirs. These results provide clues to not only the distribution of subsurface volatile reservoirs but also the long-term stability of subsurface volatiles in specific regions of Mars.

\section{Methodology}

[9] We used the information in the Barlow Catalog of Large Martian Impact Craters to conduct this study. The Catalog contains information on 42,283 impact craters 

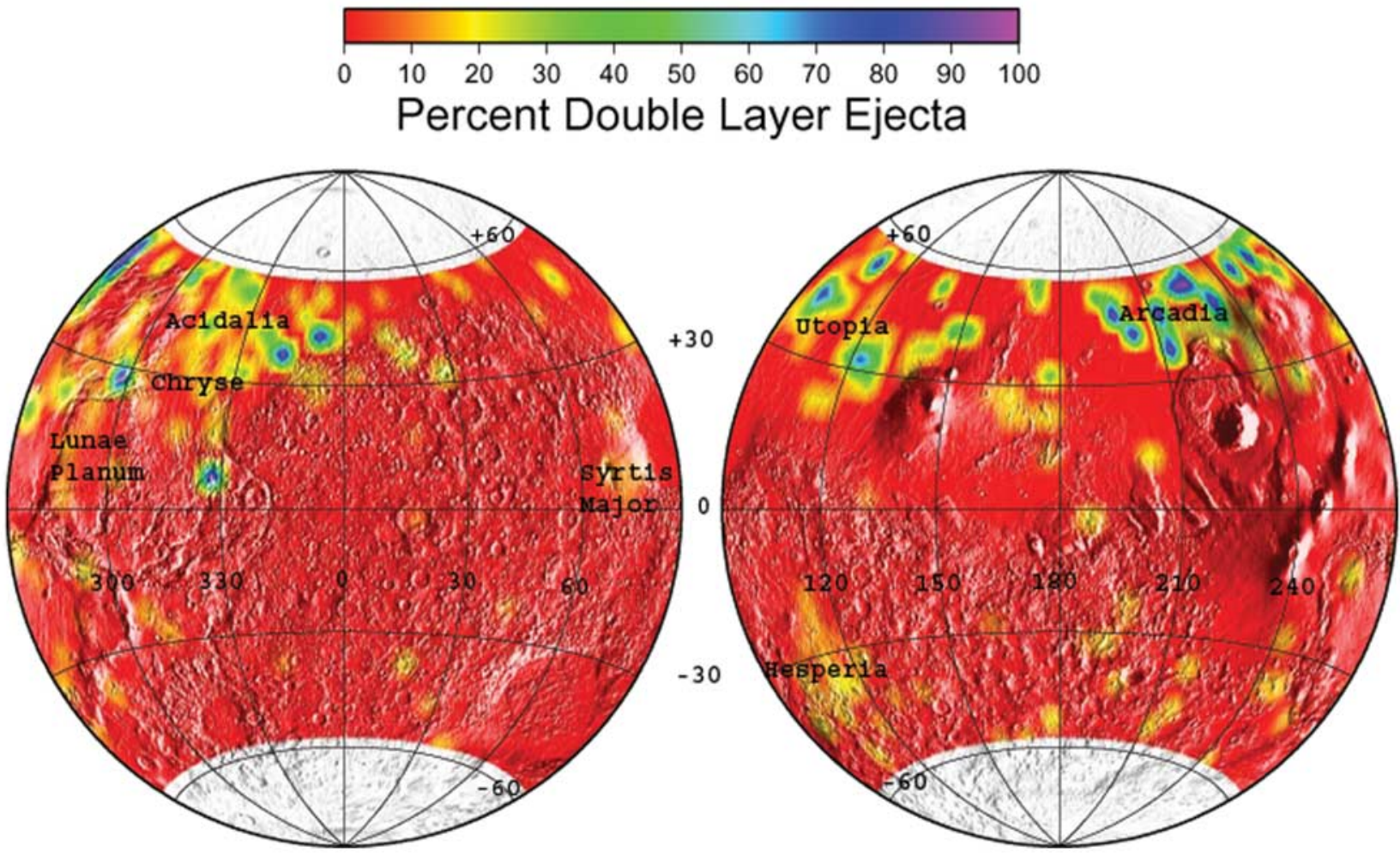

Figure 5. Percentage of DLE craters. This map shows the distribution of DLE craters as a function of the total number of ejecta craters in each $5^{\circ} \times 5^{\circ}$ latitude-longitude box. Concentrations can be seen primarily in the northern plains, with minor concentrations on some of the ridged plains regions.

$\geq 5$-km-diameter distributed across the entire planet. Catalog entries contain information about the crater location, size, stratigraphic unit, ejecta morphology (if any), interior morphology (if any), and preservational state [Barlow, 2000]. The data were originally obtained from the Viking Orbiter missions but are currently being revised using Mars Global Surveyor data. The resolutions used in this study are typically around $40 \mathrm{~m} /$ pixel since most of the study area has been imaged at this resolution. The study divides the planet into $5^{\circ} \times 5^{\circ}$ latitude-longitude boxes in the $\pm 60^{\circ}$ latitude range. We computed the percentage of craters in each $5^{\circ} \times 5^{\circ}$ latitude-longitude box for each of the following conditions: (1) Percentage of craters displaying any ejecta morphology as a function of total number of craters, (2) Percentage of craters displaying a SLE morphology as a function of total number of ejecta craters, (3) percentage of craters displaying a DLE morphology as a function of total number of ejecta craters, and (4) percentage of craters displaying a MLE morphology as a function of total number of ejecta craters. Maps of these distributions are shown in Figures 3, 4, 5, and 6.

[10] One problem with this technique is that our results suffer from the statistics of small sample sizes due to the small number of craters typically found in each $5^{\circ} \times 5^{\circ}$ latitude-longitude box. This can be alleviated in two ways: (1) increase the number of craters in each box by including smaller craters, or (2) increase the size of each box. However, even utilizing MGS Mars Orbiter Camera (MOC) wide-angle imagery to include the smaller craters, we find the onset diameter for SLE morphologies in most of the equatorial region to be around $5 \mathrm{~km}$, consistent with Viking-based analyses, although some regional variations do occur [Kuzmin et al., 1988; Boyce et al., 2000; Barlow et $a l ., 2001]$. This also has no effect on the results for the MLE craters since this morphology is typically found around larger craters (typically $>15 \mathrm{~km}$ diameter). As a result, we have gravitated to the second method of improving our statistics by looking at larger regions (but which are still small enough to provide information on regional variations). Specifically, we only consider concentrations of specific ejecta morphologies to be valid if several adjacent boxes in the region show similar trends.

\section{Results}

\subsection{Ejecta Craters}

[11] Figure 3 shows the percentage of craters displaying any type of ejecta morphology as a function of total number of craters in each $5^{\circ} \times 5^{\circ}$ box. This map correlates well with the geologic units of Mars [Tanaka, 1986; Barlow, 1988]. Noachian-aged units correlate with the areas on Figure 3 where the percentage of ejecta craters is less than about $30 \%$ while areas with ejecta crater percentages between $30 \%$ and $69 \%$ generally correlate with Hesperian-aged units. Amazonian-aged units either show high percentages of ejecta craters $(>70 \%)$ or show very few craters $<10 \%$. These youngest regions often show a mixture of very high percentage values and very low percentage values, such as is seen in the Tharsis volcanic region. This is a result of the very low numbers of craters of any type in this region- 

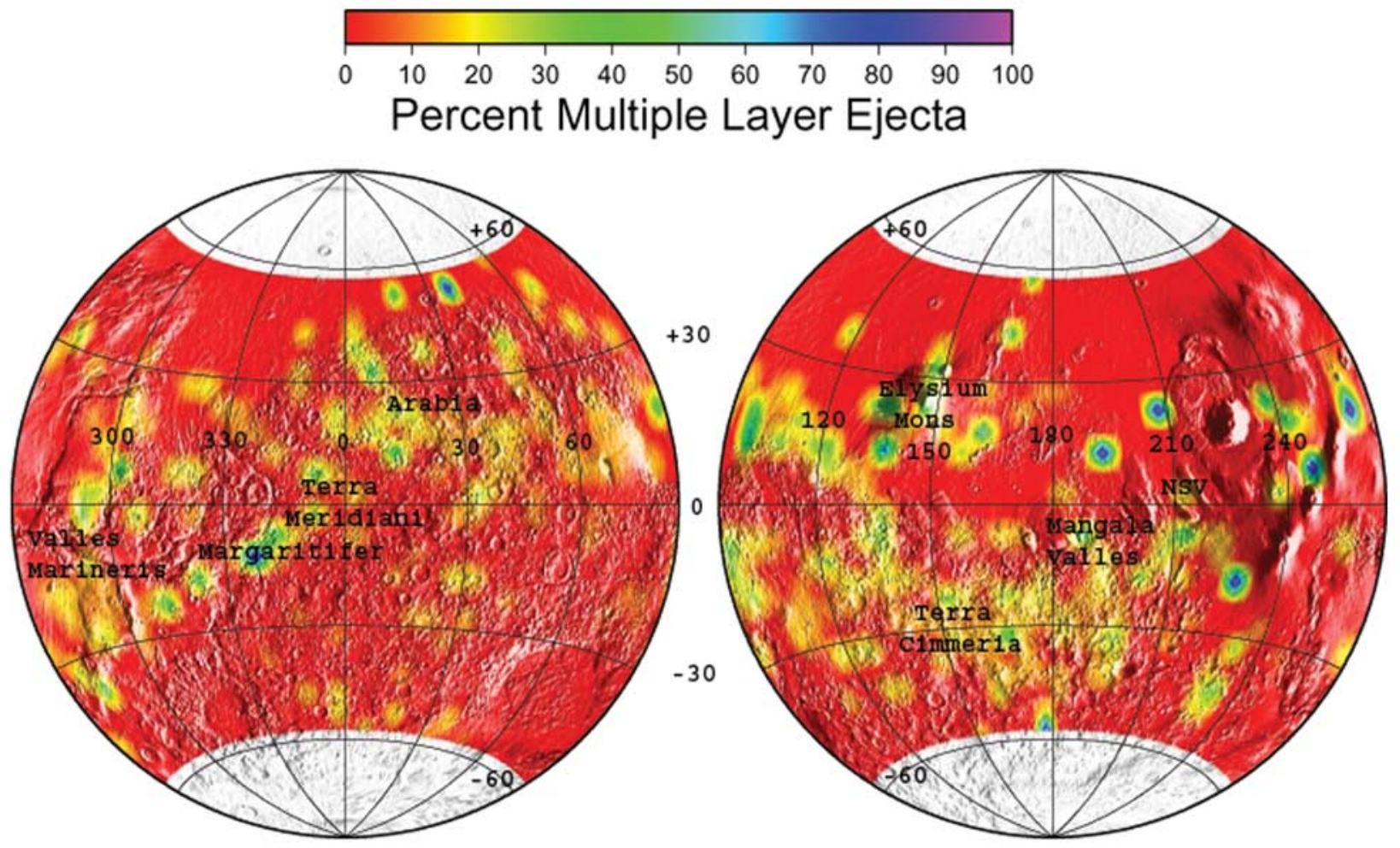

Figure 6. Percentage of MLE craters. This map shows the distribution of MLE craters as a function of the total number of ejecta craters in each $5^{\circ} \times 5^{\circ}$ latitude-longitude box. MLE craters are preferentially located on heavily cratered highlands material near the highlands-plains dichotomy boundary.

either no craters exist in the entire $5^{\circ} \times 5^{\circ}$ box (resulting in $0 \%$ ) or the few which do are all fresh craters with a discernible ejecta (resulting in $\sim 100 \%$ ).

\subsection{Single Layer Ejecta Craters}

[12] Figure 4 shows the percentage of SLE craters as a function of all ejecta craters (this includes ejecta morphologies in addition to the three dominant types considered here (see Barlow and Bradley [1990] and Barlow et al. [2000] for discussion of the other ejecta types)). SLE craters obviously dominate among the ejecta morphologies across the area of study, and in fact dominate across the entire planet, as other researchers have previously noted. Few areas exist where the percentage of SLE craters falls below $50 \%$, and this percentage exceeds $70 \%$ for most of the study area. The largest exception is again the Tharsis volcanic region where few craters of any type occur. Comparing Figure 4 with Figures 5 and 6 shows that the areas other than Tharsis where SLE craters drop below $70 \%$ are the areas where the percentages of DLE or MLE craters increase.

\subsection{Double Layer and Multiple Layer Ejecta Craters}

[13] Figure 5 shows the percentage of DLE craters as a function of all ejecta craters and Figure 6 shows the corresponding data for MLE craters. The overall numbers of DLE and MLE craters are smaller than for SLE craters, but regional concentrations can be more easily discerned for these morphologies. Figure 5 shows that DLE craters tend to be concentrated in the northern plains, particularly at latitudes between $40^{\circ} \mathrm{N}$ and $60^{\circ} \mathrm{N}$ (the latter of course may be an artificial limit since this is the boundary of the current study, but Barlow and Bradley [1990] note that DLE craters do not extend much beyond $60^{\circ} \mathrm{N}$ ). The largest concentrations of DLE craters occur in Utopia Planitia, Chryse Planitia (especially in the outwash regions of channels such as Tiu, Simund, and Ares), Acidalia Planitia, and Arcadia Planitia. The concentrations of DLE craters in Utopia and Chryse Planitiae have been noted previously by Costard [1989, 1994], Costard and Kargel [1995], and Demura and Kurita [1998]. Minor concentrations of DLE craters are suggested on some of the ridged plains regions, particularly Hesperia Planum, Syrtis Major Planum, and the western part of Lunar Planum near Kasei Valles.

[14] MLE craters are primarily concentrated in the heavily cratered highlands of Mars, especially along the dichotomy boundary in Arabia Terra, Terra Cimmeria, Margaritifer Terra, and the Mangala Valles region. There are also high concentrations in the outwash regions of the north slope valleys (NSVs) southwest of Olympus Mons [Dohm et al., 2000], near Elysium Mons, and surrounding Valles Marineris.

\section{Discussion}

[15] From the current analysis, we can state the following observations regarding the distributions of the SLE, DLE, and MLE crater morphologies on Mars:

[16] - SLE morphologies dominate across the entire $\pm 60^{\circ}$ latitude zone. SLE craters dominate up to about $20-\mathrm{km}-$ diameter within about $30^{\circ}$ of the equator and are found around craters as large as $60 \mathrm{~km}$ at higher latitudes. 
[17] - DLE morphologies are primarily concentrated in the northern plains regions of Mars, especially between $35^{\circ} \mathrm{N}$ and $60^{\circ} \mathrm{N}$. The three major concentrations in this area occur within topographic depressions (Utopia, Chryse/Acidalia, and Arcadia). The diameter range of DLE craters overlaps with that of SLE craters, typically falling in the $5 \mathrm{~km}$ to $30 \mathrm{~km}$ diameter range. Smaller concentrations of DLE morphologies are suggested in the ridged plains regions.

[18] - MLE morphologies are concentrated along the highlands-lowland dichotomy boundary. They are particularly prevalent in the same regions where valley networks and outflow channels originate (i.e., within the drainage basins of these features). Diameters of MLE craters are larger than for SLE or DLE craters, with typical values falling between $20 \mathrm{~km}$ and $45 \mathrm{~km}$.

[19] Using the Barlow and Bradley [1990] hypothesis that the SLE morphology results from impact into ice, the DLE morphology is due to impact into layered target materials with varying volatile concentrations, and the MLE morphology results from excavation into liquid-rich reservoirs, we can interpret our current results in terms of the distribution of subsurface volatiles. The dominance of the SLE morphology throughout the study region indicates that near-surface ice is prevalent across all of Mars.

[20] The depth of this ice layer can be computed using depth-diameter relationships for Martian impact craters. Garvin et al. [2000] has found that fresh complex (>7-kmdiameter) craters in the non-polar regions of Mars follow a power law of the form

$$
\mathrm{d}=0.19 \mathrm{D}^{0.55}
$$

where $d$ is the depth of the crater measured from the top of the rim to the lowest point on the crater floor and D is the rim-to-rim diameter of the crater. However, the current depth of a complex crater is likely not the same as the original excavation depth due to wall collapse, infilling, relaxation, etc. An empirically derived equation relating the transient crater excavation depth $\left(\mathrm{d}_{\mathrm{e}}\right)$ to the current rimdiameter of the crater $\left(\mathrm{D}_{\mathrm{a}}\right)$ was provided by Garvin et al. [2000] on the basis of work by Croft [1980]:

$$
\mathrm{d}_{\mathrm{e}}=0.131 \mathrm{D}_{\mathrm{a}}^{0.85}
$$

Using this relationship, we find that SLE craters in the $\pm 30^{\circ}$ latitude zone are excavating in the 0.6 to $1.5 \mathrm{~km}$ depth zone. This implies that ice reservoirs are located within $600 \mathrm{~m}$ of the surface throughout the equatorial region of Mars and extend to depths of about $2 \mathrm{~km}$ or greater at higher latitudes. These estimates should be considered average values since many uncertainties exist, such as how much ice is needed to produce the layered ejecta morphologies and whether estimates should only be made for the area from which the ejecta is derived (about $1 / 3$ the transient crater depth) or from the entire excavation depth [Barlow et al., 2001].

[21] The concentrations of DLE craters in the northern hemisphere of Mars correlate with regions which likely contain water-deposited sediments. The Utopia Basin is a topographic low which has been suggested to have contained a water-filled lake during warmer and wetter episodes in Martian history [Head et al., 1998]. The entire northern plains has been proposed to have contained an ocean during one or more episodes of Martian history due to its low topography and smoothness [Baker et al., 1991; Parker et al., 1993; Smith et al., 1999]. The Chyrse Basin is the depositional region for the circum-Chryse outflow channels and would also have hosted a large lake during any warm, wet episodes. The previous proposals that the DLE morphology results from impact into layered targets with varying volatile concentrations is consistent with our findings that these craters are preferentially located in areas which likely contain volatile-rich sedimentary deposits. The smaller concentrations of DLE craters in the ridged plains regions is also consistent with the idea of layered target materials since these plains are proposed to consist of layers of basaltic lava flows deposited in multiple eruptions [Mouginis-Mark et al., 1992] which may contain perched aquifers. The diameters of craters exhibiting the DLE morphology suggest that the layered ice reservoirs involved lie within $1.2 \mathrm{~km}$ of the surface.

[22] Hydrocode modeling by Stewart et al. (submitted manuscript, 2003) suggests that the MLE morphology results from the interaction of the vapor curtain with the atmosphere during crater formation. However, the regional distribution of the MLE morphology suggests that variations in subsurface properties must also be involved. The distribution of MLE craters correlates with the drainage areas of many of the valley networks and outflow channels, supporting the proposal by Barlow and Bradley [1990] that subsurface liquid water reservoirs may play a role in the formation of the MLE morphology. The concentration of MLE craters in the Arabia Terra region overlaps with the Terra Meridiani hematite deposit [Christiansen et al., 2000], which likely had a hydrothermal origin. If the MLE morphology is the result of impact into liquid water reservoirs, the diameter range of these craters suggests that liquid water lies between 1.5 and $5 \mathrm{~km}$ below the surface in these regions.

[23] The Gamma Ray Spectrometer (GRS ) instrument on the Mars Odyssey mission is providing new evidence for the distribution of near-surface $\mathrm{H}_{2} \mathrm{O}$. The Neutron Spectrometer (part of the GRS instrument) has detected regions with low fluxes of epithermal neutrons, which are likely being absorbed by hydrogen in the crust (Figure 7). Since hydrogen is most commonly found bound with oxygen in the water molecule, the detection of regions with low epithermal neutron flux is interpreted to indicate regions of near-surface $\mathrm{H}_{2} \mathrm{O}$ in the Martian crust [Boynton et al., 2002; Feldman et al., 2002]. The regions cited as being $\mathrm{H}_{2} \mathrm{O}$-rich on the basis of the GRS results correlate with many of the regions where our crater analysis finds strong concentrations of DLE and MLE craters. For example, we find a concentration of the MLE morphology along the dichotomy boundary, particularly west of the Tharsis region, and in Arabia Terra. Both of these regions display low epithermal neutron fluxes suggesting the presence of nearsurface $\mathrm{H}_{2} \mathrm{O}$. Many of the regions where DLE craters are concentrated, particularly in Utopia and Arcadia, are among the regions with the highest concentrations of $\mathrm{H}_{2} \mathrm{O}$ based on the GRS results. Although the correspondence is not exact (for example, we find a high concentration of MLE craters in Solis Planum where GRS reports a low concentration of $\mathrm{H}_{2} \mathrm{O}$ ) and the depths reported by the two techniques are 


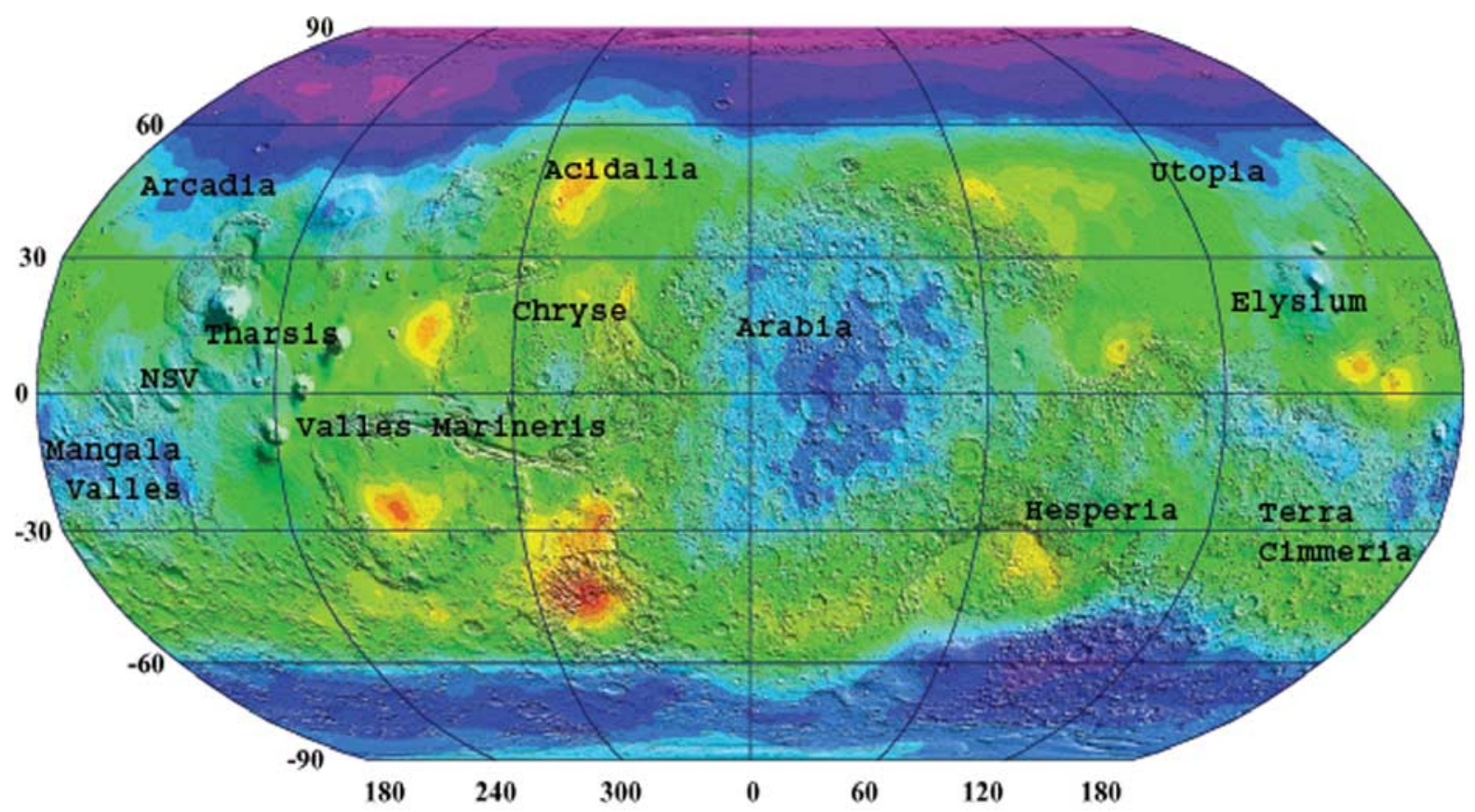

\section{Epithermal Neutrons}

$\mathrm{H}_{2} \mathrm{O}$-Rich $\quad \mathrm{H}_{2} \mathrm{O}-\mathrm{Poor}$

Figure 7. GRS epithermal neutron map. This map shows the distribution of the epithermal neutron flux as measured by the Neutron Spectrometer (part of the GRS instrument package) during northern hemisphere summer. Comparison of this map with Figures 5 and 6 shows a general correlation of regions with low epithermal neutron flux (interpreted as high water concentration) with the highest concentrations of DLE and MLE craters. The color scheme in Figures 3 through 6 has been selected so that regions of high crater concentrations are the same color as regions proposed to be of high water content on this figure. (Map courtesy of William Boynton and the GRS Science Team).

quite different $(\sim 1$ meter for GRS versus hundreds of meters to kilometers from the craters), the GRS results generally correlate with regional concentrations of DLE and MLE morphologies. This suggests that volatiles in the deeper reservoirs sampled by the impact craters are able to diffuse to the near-surface regions sampled by the GRS instruments. The concentration of DLE craters in areas of possible sediments and of MLE craters in heavily cratered and otherwise dissected (e.g., by channels) material suggest that these regions may be more porous to allow the transport of volatiles between deeper to shallower regions.

[24] However, there are several potential complications with this simple model. Variations in the lithologic properties of the target with depth may play a role in the formation of different ejecta morphologies. Schultz and his colleagues [Schultz and Gault, 1979; Schultz, 1992; Barnouin-Jha and Schultz, 1998] have argued that variations in target properties such as grain size can affect the number of flow lobes produced for a crater of a given size. The combination of grain size together with the presence of subsurface volatiles may help to reconcile the regional distributions of MLE craters noted here with Stewart et al.'s (submitted manuscript, 2003) computer models which show that this mor- phology results from interaction of the ejecta vapor curtain with the planet's atmosphere. A more thorough understanding of the role that target properties play in the formation of the ejecta morphologies may be obtained by the Mars Express MARSIS experiment which will use radar to map subsurface lithologic boundaries [Marinangeli et al., 2001].

[25] Another complication is the possible temporal variation in the concentration, physical state, and distribution of subsurface volatiles over time. The geothermal heat flow of the planet has almost certainly declined with time and obliquity variations may have caused significant climatic shifts. Since the technique utilized in this study uses impact craters which have formed throughout the planet's history, our results may not be telling us anything about the current distribution of subsurface volatile reservoirs. However, a study by Mellon and Jakosky [1995] finds that obliquity variations will not affect subsurface volatile reservoirs at the depths of interest in this study. In addition, a study of the extent of the ejecta lobes (believed to be an indicator of the concentration of volatiles in the target at the time of impact) with preservational state of the crater (related to crater age) has not found any significant variations [Barlow, 2003]. The current best estimates of the Martian heat flux suggest that 
$\mathrm{H}_{2} \mathrm{O}$ could still be in the liquid state at depths greater than about $1.5 \mathrm{~km}$ in the equatorial region and possibly closer to the surface if the reservoirs are briny [Clifford, 1993]. These studies suggest that the locations and physical states of the volatile reservoirs have not changed dramatically over the time period recorded by these craters (stretching back as far as the end of late heavy bombardment (middle of the Hesperian) on the basis of crater statistical studies [Barlow, 1990]). Again, the Mars Express MARSIS experiment may be able to provide better constraints regarding the characteristics of the present-day subsurface volatile reservoirs.

\section{Conclusions}

[26] This study confirms previous reports that the SLE morphology is the dominant ejecta morphology for relatively fresh impact craters on Mars. On the basis of models for the distribution of subsurface volatiles [Clifford, 1993] we agree with previous suggestions that the SLE morphology results from impact into subsurface ice and that this ice is prevalent throughout the near-surface region of Mars. Our study of the DLE and MLE morphologies reveals several new results, which can be summarized as follows:

[27] • Craters displaying the DLE morphology are concentrated primarily in topographic lows which may have served as cachement basins for sediments from outflow channels or past lakes/oceans. In addition to the concentration of DLE craters in Chryse and Utopia (noted previously by Costard [1989, 1994], Costard and Kargel [1995], and Demura and Kurita [1998]), this study also finds concentrations within Arcadia and Acidalia. These results support earlier suggestions that impact into layered target materials whose layers contain varying concentrations of volatiles may produce the DLE morphology.

[28] - This study provides the first detailed analysis of the distribution of craters displaying the MLE morphology. We find that MLE craters concentrate along the dichotomy boundary and in areas displaying channels such as those near Elysium and Tharsis. We believe that the correlation of MLE morphology craters with features such as channels and other indicators of liquid water in these regions argues for the idea that the MLE morphology can be used to identify regions with subsurface liquid water reservoirs [Barlow and Bradley, 1990]. However, the models by Stewart et al. (submitted manuscript, 2003) showing that atmospheric effects contribute to the formation of this morphology indicate that other factors may complicate this simple scenario. The regional variations in MLE distribution suggests that target properties do play a role, but determining whether the MLE morphology is an indicator of subsurface liquid reservoirs may need to await direct investigation of volatiles in the substrate by instruments such as the MARSIS radar system or the seismic network of Netlander.

[29] $\bullet$ The DLE and MLE morphology distributions show a general correlation with many areas of high water content, as indicated by the Mars Odyssey Gamma Ray Spectrometer results. Since the GRS results provide data about $\mathrm{H}_{2} \mathrm{O}$ in the upper meter of the surface and the impact craters provide information about such reservoirs at depths on the order of hundreds of meters to kilometers, the correlation suggests that volatile exchange may occur between these regions over long time periods.
[30] On the basis of the depth analysis, consistency with the proposed distribution of subsurface volatiles based on theoretical considerations [Clifford, 1993], and the comparison with GRS data [Boynton et al., 2002], it appears that fresh Martian impact craters displaying any of the three layered ("fluidized") ejecta morphologies are likely providing important information about the distribution of subsurface $\mathrm{H}_{2} \mathrm{O}$ and perhaps its physical state. These craters provide a global perspective of the potential volatile resources of the planet and are an inexpensive way to identify the most promising locations for future detailed geophysical studies of the distribution of subsurface volatiles on Mars.

[31] Acknowledgments. We thank Francois Costard, Joe Boyce, and an anonymous reviewer for their constructive comments to improve the manuscript, Robert Marcialis for assistance in producing Figures 3 through 6, and William Boynton and the GRS Team for the epithermal neutron map in Figure 7. This work was supported by NASA MDAP grant NAG58265 to NGB and Florida Space Grant Consortium funding to CBP.

\section{References}

Allen, C. C., Areal distribution of rampart craters on Mars, in Reports of Planetary Geology Program 1977-1978, NASA Tech. Memo., 79729, 160-161, 1978.

Baker, V. R., R. G. Strom, V. C. Gulick, J. S. Kargel, G. Komatsu, and V. S. Kale, Ancient oceans, ice sheets and the hydrological cycle on Mars, Nature, 352, 589-594, 1991.

Baratoux, D., C. Delacourt, and P. Allemand, An instability mechanism in the formation of the Martian lobate craters and the implications for the rheology of ejecta, Geophys. Res. Lett., 29(8), 1210, doi:10.1029/ 2001GL013779, 2002

Barlow, N. G., Crater size-frequency distributions and a revised Martian relative chronology, Icarus, 75, 285-305, 1988.

Barlow, N. G., Constraints on early events in Martian history as derived from the cratering record, J. Geophys. Res., 95, 14,191-14,201, 1990.

Barlow, N. G., Sinuosity of Martian rampart ejecta deposits, J. Geophys. Res., 99, 10,927-10,935, 1994.

Barlow, N. G., Updates to the "Catalog of Large Martian Impact Craters," Lunar Planet. Sci., XXXIV, abstract 1475, 2000.

Barlow, N. G., Has the volatile content of the Martian substrate varied over time?, Lunar Planet. Sci., XXXIV, abstract 1122, 2003.

Barlow, N. G., and T. L. Bradley, Martian impact craters: Correlations of ejecta and interior morphologies with diameter, latitude, and terrain, Icarus, 87, 156-179, 1990.

Barlow, N. G., J. M. Boyce, F. M. Costard, R. A. Craddock, J. B. Garvin, S. E. H. Sakimoto, R. O. Kuzmin, D. J. Roddy, and L. A. Soderblom, Standardizing the nomenclature of Martian impact crater ejecta morphologies, J. Geophys. Res., 105, 26,733-26,738, 2000.

Barlow, N. G., J. Koroshetz, and J. M. Dohm, Variations in the onset diameter for Martian layered ejecta morphologies and their implications for subsurface volatile reservoirs, Geophys. Res. Lett., 28, 3095-3098, 2001.

Barnouin-Jha, O. S., and P. H. Schultz, Lobateness of impact ejecta deposits from atmospheric interactions, J. Geophys. Res., 103, 25,739-25,756, 1998.

Blasius, K. R., and J. A. Cutts, Global patterns of primary crater ejecta morphology on Mars, in Reports of the Planetary Geology Program 1980, NASA Tech. Memo, 82385, 147-149, 1980.

Boyce, J. M., and D. J. Roddy, Martian rampart craters: Crater processes that may affect diameter-frequency distributions, in Reports of the Planetary Geology Program 1977-1978, NASA Tech. Memo., 79729, 162165,1978 .

Boyce, J. M., and D. J. Roddy, Martian crater ejecta, emplacement, and implications for water in the subsurface, Lunar Planet. Sci., XXVIII, 145-146, 1997.

Boyce, J. M., D. J. Roddy, and L. A. Soderblom, Distribution of onset diameters of rampart ejecta craters on Mars, Lunar Planet. Sci., XXIX, abstract 1404, 1998.

Boyce, J. M., D. J. Roddy, L. A. Soderblom, and T. Hare, Global distribution of on-set diameters of rampart ejecta craters on Mars: Their implications to the history of Martian water, Lunar Planet. Sci., XXXI, abstract 1167, 2000.

Boynton, W. V., et al., Distribution of hydrogen in the near-surface of Mars: Evidence for subsurface ice deposits, Science, 297, 81-85, 2002. 
Carr, M. H., L. S. Crumpler, J. A. Cutts, R. Greeley, J. E. Guest, and H. Masursky, Martian impact craters and emplacement of ejecta by surface flow, J. Geophys. Res., 82, 4055-4065, 1977.

Christensen, P. R., et al., Detection of crystalline hematite mineralization on Mars by the Thermal Emission Spectrometer: Evidence for near-surface water, J. Geophys. Res., 105, 9623-9642, 2000.

Clifford, S. M., A model for the hydrologic and climatic behavior of water on Mars, J. Geophys. Res., 98, 10,973-11,016, 1993.

Costard, F. M., The spatial distribution of volatiles in the Martian hydrolithosphere, Earth Moon Planets, 45, 265-290, 1989.

Costard, F., Unusual concentrations of rampart craters at the mouths of outflow channels, Mars, Lunar Planet. Sci., XXV, 287-288, 1994.

Costard, F. M., and J. S. Kargel, Outwash plains and thermokarst on Mars, Icarus, 114, 93-112, 1995.

Croft, S. K., Cratering flow fields: Implications for the excavation and transient expansion stages of crater formation, Proc. Lunar Planet. Sci. Conf. 11th, 2347-2378, 1980.

Demura, H., and K. Kurita, A shallow volatile layer at Chyrse Planitia, Mars, Earth Planets Space, 50, 423-429, 1998.

Dohm, J. M., R. C. Anderson, V. R. Baker, J. C. Ferris, T. M. Hare, R. G. Strom, L. P. Rudd, J. W. Rice, R. R. Casavant, and D. H. Scott, System of gigantic valleys northwest of Tharsis, Mars: Latent catastrophic flooding, northwest watershed, and implications for northern plains ocean, Geophys. Res. Lett., 27, 3559-3562, 2000.

Fanale, F. P., Martian volatiles: Their degassing history and geochemical fate, Icarus, 28, 179-202, 1976.

Feldman, W. C., et al., Global distribution of neutrons from Mars: Results from Mars Odyssey, Science, 297, 75-78, 2002.

Garvin, J. B., S. E. H. Sakimoto, J. J. Frawley, and C. Schnetzler, North polar region craterforms on Mars: Geometric characteristics from the Mars Orbiter Laser Altimeter, Icarus, 144, 329-352, 2000.

Gault, D. E., and R. Greeley, Exploratory experiments of impact craters formed in viscous-liquid targets: Analogs for Martian rampart craters?, Icarus, 34, 486-495, 1978

Greeley, R., J. Fink, D. E. Gault, D. B. Snyder, J. E. Guest, and P. H. Schultz, Impact cratering in viscous targets: Laboratory experiments, Proc. Lunar Planet. Sci. Conf 11th, 2075-2097, 1980.

Head, J. W., and R. Roth, Mars pedestal crater escarpments: Evidence for ejecta-related emplacement, in Papers Presented to the Symposium on Planetary Cratering Mechanics, pp. 50-52, Lunar Sci. Inst., Houston, Tex., 1976

Head, J. W., M. Kreslavsky, H. Hiesinger, M. Ivanov, S. Pratt, N. Siebert, D. E. Smith, and M. T. Zuber, Oceans in the past history of Mars: Tests for their presence using Mars Orbiter Laser Altimeter (MOLA) data, Geophys. Res. Lett., 25, 4401-4404, 1998

Hoffman, N., White Mars: A new model for Mars' surface and atmosphere based on $\mathrm{CO}_{2}$, Icarus, 146, 326-342, 2000

Horner, V. M., and R. Greeley, Effects of elevation and ridged plains thicknesses on Martian crater ejecta morphology, Proc. Lunar Planet. Sci. Conf. 17th, Part 2, J. Geophys. Res., 92, suppl., E561-E569, 1987.

Johansen, L. A., Martian splosh cratering and its relation to water, paper presented at 2nd Colloquium on Planetary Water and Polar Processes, NASA, Hanover, N. H., 1978.

Johansen, L. A., The latitude dependence of Martian splosh cratering and its relationship to water, in Reports of the Planetary Geology Program 1978-1979, NASA Tech. Memo., 80339, 123-125, 1979.

Kargel, J. S., First and second-order equatorial symmetry of Martian rampart crater ejecta morphologies (abstract), paper presented at Fourth International Conference on Mars, Univ. of Ariz., Tucson, 1989.

Kuzmin, R. O., N. N. Bobina, E. V. Zabalueva, and V. P. Shashkina, Structural inhomogeneities of the Martian cryosphere, Sol. Syst. Res., $22,121-133,1988$.
Lucchitta, B. K., and H. M. Ferguson, Chryse basin channels: Low-gradients and ponded flows, Prof. Lunar Planet. Sci. Conf. 13th, Part 2, J. Geophys. Res., 88, suppl., A553-A568, 1983.

Malin, M. C., and K. S. Edgett, Evidence for recent ground-water seepage and surface runoff on Mars, Science, 288, 2325-2330, 2000.

Marinangeli, L., J. Ormo, G. G. Ori, and A. Baliva, Investigating the subsurface geology of Mars using the MARSIS radar instrument of the Mars Express Mission, Lunar Planet. Sci., XXXII, abstract 1537, 2001.

Max, M. D., and S. M. Clifford, Initiation of Martian outflow channels: Related to the dissociation of gas hydrate?, Geophys. Res. Lett., 28, 1787-1790, 2001.

Mellon, M. T., and B. M. Jakosky, The distribution and behavior of Martian ground ice during past and present epochs, J. Geophys. Res., 100, $11,781-11,799,1995$

Melosh, H. J., Impact Cratering: A Geologic Process, 245 pp., Oxford Univ. Press, New York, 1989.

Mouginis-Mark, P., Martian fluidized crater morphology: Variations with crater size, latitude, altitude, and target material, J. Geophys. Res., 84, $8011-8022,1979$

Mouginis-Mark, P., Ejecta emplacement and modes of formation of Martian fluidized ejecta craters, Icarus, 45, 60-76, 1981.

Mouginis-Mark, P. J., Water or ice in the Martian regolith? Clues from rampart craters seen at very high resolution, Icarus, 71, 268-286, 1987.

Mouginis-Mark, P. J., L. Wilson, and M. T. Zuber, The physical volcanology of Mars, in Mars, edited by H. H. Kieffer et al., pp. 424-452, Univ. of Ariz. Press, Tucson, 1992.

Musselwhite, D. S., T. D. Swindle, and J. I. Lunine, Liquid $\mathrm{CO}_{2}$ breakout and the formation of recent small gullies on Mars, Geophys. Res. Lett., 28, 1283-1285, 2001.

Mutch, P., and A. Woronow, Martian rampart and pedestal craters' ejectaemplacement: Coprates Quadrangle, Icarus, 41, 259-268, 1980.

Parker, T. J., D. S. Gorsline, R. S. Saunders, D. Pieri, and D. M. Schneeberger, Coastal geomorphology of the Martian northern plains, J. Geophys. Res., 98, 11,061-11,078, 1993.

Saunders, R. S., and L. A. Johansen, Latitudinal distribution of flowejecta morphology types on the ridged plains of Mars, paper presented at 3rd Colloquium on Planetary Water, NASA, Niagara Falls, N. Y., 1980 .

Schultz, P. H., Atmospheric effects on ejecta emplacement and crater formation on Venus from Magellan, J. Geophys. Res., 97, 16,183-16,248, 1992.

Schultz, P. H., and D. E. Gault, Atmospheric effects on Martian ejecta emplacement, J. Geophys. Res., 84, 7669-7687, 1979.

Smith, D. E., et al., The global topography of Mars and implications for surface evolution, Science, 284, 1495-1503, 1999.

Stewart, S. T., and F. Nimmo, Surface runoff features on Mars: Testing the carbon dioxide formation hypothesis, J. Geophys. Res., 107(E9), 5069, doi:10.1029/2000JE001465, 2002.

Tanaka, K. L., The stratigraphy of Mars, Proc. Lunar Planet. Sci. Conf. 17th, Part 1, J. Geophys. Res., 91, suppl., E139-E158, 1986.

Wohletz, K. H., and M. F. Sheridan, Martian rampart crater ejecta: Experiments and analysis of melt-water interaction, Icarus, 56, 15-37, 1983.

Woronow, A., Preflow stresses in Martian rampart ejecta blankets: A means of estimating the water content, Icarus, 45, 320-330, 1981.

N. G. Barlow, Department of Physics and Astronomy, Northern Arizona University, NAU Box 6010, Flagstaff, AZ 86011-6010, USA. (Nadine. Barlow@nau.edu)

C. B. Perez, College of Engineering and Computer Science, University of Central Florida, Orlando, FL 32816, USA. 